\title{
POR UMA HISTÓRIA DA APRECIAÇÃO MUSICAL NA ESCOLA BRASILEIRA: AS IDEIAS DISPOSTAS NOS MANUAIS DIDÁTICOS DO CANTO ORFEÔNICO
}

\author{
POR UNA HISTORIA DE LA APRECIACIÓN MUSICAL EN LA ESCUELA \\ BRASILEÑA: LAS IDEAS DISPOSTAS EN LOS MANUALES DIDÁCTICOS DEL \\ CANTO ORFEÓNICO
}
FOR A HISTORY OF LISTENING IN THE BRAZILIAN SCHOOL: THE IDEAS DISPOSED IN THE TEACHING GUIDES OF THE ANCIENT CHORAL SINGING GROUPS

Paulo CONSTANTINO ${ }^{1}$

RESUMO: Reconstitui os percursos da atividade de apreciação musical na escola brasileira, compondo uma historiografia sobre elementos que são mínimos e esparsos, por meio de pesquisa bibliográfica. A ênfase recai sobre o período de desenvolvimento e vigência oficial do Canto Orfeônico [entre as décadas de 1930-1960] no país, do qual se apresentam as ideias sobre apreciação presentes em sete manuais didáticos difundidos à época. A predominância dos aspectos de performance e educação cívica no Canto Orfeônico relegaram a apreciação como atividade pedagógica a um plano secundário, e seu reconhecimento será posto somente após a segunda metade do século XX: por razões tecnológicas, com a popularização das gravações ou registros fonográficos; e pela introdução de uma literatura no país que reconheceria o caráter basilar da atividade nos processos de educação musical.

PALAVRAS-CHAVE: História da educação musical. Apreciação musical. Cultura escolar. Canto orfeônico.

RESUMEN: Reconstituye los caminos de la apreciación musical en la escuela brasileña, al componer una historiografía sobre elementos que son mínimos, por medio de la investigación bibliográfica. El énfasis recae sobre el período de desarrollo y vigencia oficial del Canto Orfeônico [coros en las escuelas entre las décadas de 19301960], del cual se presentan las ideas sobre apreciación presentes en siete manuales didácticos difundidos en la época. El predominio de la educación civica y la performance no Canto Orfeônico se han relegado la apreciación como actividad pedagógica a un plano secundario, y su reconocimiento será posto sólo después de una segunda mitad del siglo XX: por razones tecnológicas, con una popularización de las gravaciones; y la introducción de una literatura que reconoce el carácter basilar de la actividad en los procesos de educación musical.

${ }^{1}$ Universidade Estadual Paulista (UNESP), Marília - SP - Brasil. Professor substituto no Departamento de Administração e Supervisão Escolar da Unesp Marília. Atua na supervisão escolar das escolas técnicas estaduais de São Paulo. ORCID: <http://orcid.org/0000-0002-4612-4063>. E-mail: pconst2@gmail.com.br 
PALABRAS CLAVE: História de la educación musical. Apreciación musical. Cultura escolar. Coros.

ABSTRACT: It reconstructs the paths of musical listening in the Brazilian school, composing a historiography on elements that are minimal, through bibliographical research. The emphasis is on the period of development of the 'Canto Orfeonico' [choral singing groups between the decades of 1930-1960] in the country, which presents the ideas about listening present in seven guides published at the time. The predominance of performance and civic education in the groups relegated the listening as a pedagogical activity to a secondary plane, and its recognition will be placed only after the second half of the twentieth century: for technological reasons, with the popularization of recordings; and by the introduction of a literature that would recognize the basic character of the activities in musical education.

KEYWORDS: Music history. Listening. Schooling culture. Choral groups [Orfeonico's Singing Groups]

\section{Introdução}

A ausência de informações sobre a apreciação musical na educação básica do Brasil sugere que seu tratamento era raro no âmbito escolar e nos manuais didáticos disponíveis durante a maior parte do século XX e anteriormente. Reconstituir estes percursos históricos é, portanto, tarefa árdua, ao lembrar que "no Brasil ainda temos pouca experiência com a pesquisa em história da educação musical" (SOUZA, 2014, p. 112). Rita Fucci-Amato (2006, p. 145) corroborava esta afirmação, informando que a investigação histórica relativa à educação musical brasileira não tinha mais do que um quarto de século na ocasião. O período referido pela autora coincide com o da multiplicação dos cursos superiores pelo país, o fortalecimento de entidades de classe e a inserção e difusão de diferentes autores e propostas educacionais, a partir da segunda metade dos anos de 1980 .

Apesar da jovialidade do campo, tento localizar uma história da apreciação musical na escola brasileira, dentre as várias histórias da educação musical que estão sendo redigidas até o momento no país, como

[...] a história das instituições; a história de movimentos pedagógicomusicais, como a história do canto orfeônico, no Brasil; a história dos cursos superiores de música no Brasil; a história do ensino de música e sua institucionalização na escola; a história do ensino de música a partir das orquestras e coros; a história da educação musical analisada por meio dos chamados espaços informais; a história do ensino de 
música a partir das associações de classe, incluindo a Associação Brasileira de Educação Musical - ABEM; ou, ainda, a história da educação musical a partir dos livros didáticos (SOUZA, 2014, p. 113114).

A atividade de escuta musical ou apreciação ${ }^{2}$ se relaciona com uma audição atenta e intencional pelos indivíduos, em meio ao continuum sonoro dos lugares onde habitamos ou qualquer outra situação em que estivermos expostos aos sons. Na escola, constitui-se em tarefa a ser empreendida em dois tempos: a) como mediadora e juíza das demais atividades musicais, como a composição, improvisação e a execução e; b) como atividade autônoma, que visa o desenvolvimento dos conhecimentos específicos dos alunos, a ampliação de sua cultura geral e o acesso aos bens culturais.

Esta modalidade de escuta seria indissociável das demais atividades musicais elencadas por Keith Swanwick ${ }^{3}$ (2014), e certamente, importante em todas as experiências (SCHAFER, 2009) ou métodos ativos da educação musical. Uma vez reposta à condição de atividade prioritária para uma educação musical integradora, a apreciação musical, tal como a concebemos, não seria uma tarefa passiva, mas revestida de intencionalidade e objetivos educacionais, sob a perspectiva do professor; e de prestígio às subjetividades dos alunos, pois envolveria igualmente imaginação e criatividade (HARGREAVES et al, 2012) na resolução de problemas perceptuais e uma mente ativa na construção de estruturas e significações pelo ouvinte. Nesta perspectiva, apreciar música e entender os percursos midiáticos de uma obra torna-se um objetivo desejável para todo aluno da educação básica.

Para aprofundar estas noções educacionais da apreciação musical sob uma perspectiva histórica, os estudos relacionados às instituições escolares e movimentos pedagógico-musicais, como os de Rosa Fuks (1991, 2007), Jusamara Souza (2007; 2014), Marisa Fonterrada (2008), Rita Fucci-Amato (2006; 2007; 2012), Lenita Nogueira (2001) e as publicações organizadas por Alda Oliveira e Regina Cajazeira (2007) ou José Geraldo Moraes e Elias Saliba (2010), são alguns dos referenciais mais

\footnotetext{
2 Para nomear esta escuta atenta, que reporta a uma compreensão aprofundada da música, diferentes autores empregam expressões como "apreciação musical ativa" (BASTIÃO, 2014), "ouvir com significado" (LAZZARIN, 1999), "ouvinte inteligente ou consciente" (COPLAND, 1974); "ouvir música musicalmente" de Bennett Reimer (1989); "audição inteligente ou compreensiva" de Caldeira Filho (1971), ou "audição musical ativa", de Wuytack e Palheiros (1995).

${ }^{3} \mathrm{O}$ modelo de atividades educacionais proposto por Keith Swanwick $(2003 ; 2014)$ reúne e integra as atividades práticas relacionadas à música, o que no Brasil ficou traduzido como Sistema (T)EC(L)A de Educação Musical: (T)-Técnicas instrumentais, de percepção e notação musical; E- Execução da música, performance; C- Composição musical, improvisação; (L)- Literatura da música e sobre a música; AApreciação musical.
} 
recentes e vigorosos no país, e fundamentam as nossas reflexões. Mais do que as limitações impostas pela falta de referenciais para uma historiografia da apreciação musical na escola, como sublinham Moraes e Saliba (2010, p.11), é preciso reconhecer a dificuldade adicional de uma cartografia desta atividade, pois

[...] um aspecto a considerar é a discussão sobre possíveis origens: onde começa a educação musical no Brasil? No estado do Amazonas, os primeiros registros mencionados sobre o ensino de Música são do século XVII. Na Bahia, a vinda dos jesuítas para o primeiro Governo Geral, em 1549, assinala o início. No Rio de Janeiro, os primórdios são localizados no período colonial, no período de catequização dos nativos indígenas pelos jesuítas. E em Roraima, as notícias mais antigas estão nas expedições e viagens. Alguns autores vão correlacionar esse início com os ciclos econômicos e culturais como o ciclo da borracha, no Amazonas, ou o ciclo da mineração e a presença de um movimento artístico musical, em Goiás, no século XVIII (SOUZA, 2014, p. 111).

Em nossa pesquisa, a ênfase recaiu sobre o período de desenvolvimento e vigência oficial do Canto Orfeônico [décadas de 1930-1960] no país, do qual se elencou as ideias sobre apreciação presentes em sete [7] manuais didáticos difundidos à época por autores e editores significativos. Optou-se pelo referido período pois nele, mais do que em qualquer outro da história da educação musical brasileira, se reconhece mais nitidamente uma cultura escolar, que Dominique Julia definiu como os "conhecimentos a ensinar e condutas a inculcar, e um conjunto de práticas que permitem a transmissão desses conhecimentos e a incorporação desses comportamentos" (2001, p. 09), permitindo-nos, portanto, delinear o percurso histórico da apreciação musical na escola por meio dos projetos pedagógicos, conteúdos e repertório dispostos nas publicações.

\section{Identificando o percurso da apreciação musical escolar no país até o início do século XX}

Entre os jesuítas, tradicionalmente reconhecidos como os pioneiros na organização da educação brasileira no período colonial, "aprendia-se pela prática exaustiva, mediante exercícios que evoluíam do simples para o complexo" (FONTERRADA, 2008, p.209), de modo a permitir um domínio progressivo e racionalmente organizado, no que seria a primeira proposta para uma pedagogia musical em terras brasileiras. Um exemplo das técnicas deste duplum catequese-educação musical, praticado entre 1549 e 1759, é descrito por Paulo Castagna: 
A primeira delas consistia em ensinar um texto cristão em língua tupi, cantado com melodia europeia; a outra era ensinar um texto cristão em tupi, mas utilizando melodia e instrumentos indígenas. A segunda técnica foi proibida em 1552 e, a partir de então, somente a maneira europeia de se cantar foi permitida [ao menos, oficialmente] (CASTAGNA, 2010, p. 45).

Estes registros de canções da época não sobreviveram. O que se pode destacar é que os índios brasileiros receberam formação e puderam participar ativamente da cena musical brasileira, pelos registros que nos chegaram sobre índios músicos desde 1554, com uma prática de educação musical bem desenvolvida até 1580 (CASTAGNA, 2010).

Anos mais tarde, durante o período imperial, as práticas de ensino musicais herdadas dos europeus não sofreriam alterações significativas, ainda permanecendo atreladas aos "métodos progressivos e com grande ênfase na memorização. Ao mesmo tempo, firmava-se no país a prática informal da música popular, que não se moldava pelo conjunto de regras disciplinares de inspiração pragmática ou jesuítica" (FONTERRADA, 2008, p. 210), mas se constituía de modo espontâneo ao valorizar aspectos como a habilidade do executante ou sua capacidade de improvisação.

Ainda no contexto imperial brasileiro, em 1854, o ensino de música no país foi regulamentado por um decreto federal que

[...] passou a orientar as atividades docentes, enquanto que, no ano seguinte, um outro decreto fez exigência de concurso público para a contratação de professores de música. Na primeira república, a legislação educacional evoluiu diversamente em cada estado, fazendo com que em cada região a estrutura e o funcionamento das escolas adquirissem características muito específicas (FUCCI-AMATO, 2006, p. 147).

Os relatos e documentos oficiais que tratam das escolas durante o Império demonstram que a música era parte do currículo e considerada fundamental em uma formação educacional completa (NOGUEIRA, 2001, p. 301). Referindo-se às escolas paulistas no período da Primeira República, em 1892, Vidal e Filho (2005, p.43) relatam a presença do ensino de canto e leitura musical no programa das escolas preliminares do Estado.

Segundo Hentschke e Oliveira (2000, p. 47), o ensino de música nas escolas públicas brasileiras havia se tornado obrigatório desde o século XIX, mas foi a partir da 
criação da Superintendência de Educação Musical e Artística - SEMA ${ }^{4}$, que se tornou mais relevante, com a aplicação em larga escala do canto orfeônico e da iniciação musical por manossolfa:

\begin{abstract}
A partir da década de 1920, diversas transformações nos modelos e nas legislações relativas ao ensino de música ocorreram. Um fato relevante para a educação musical sucedeu-se no ano de 1923, quando as escolas públicas paulistas passaram a utilizar o método "tonicsolfa" como modelo de musicalização. Outro grande avanço foi a musicalização para crianças, a partir de sua instituição através de uma lei federal de 1928, a qual criou os jardins de infância com orientação especializada. (FUCCI-AMATO, 2006, p. 148)
\end{abstract}

Se não cabe aqui uma digressão sobre o pioneirismo paulista nas iniciativas do canto orfeônico e dos métodos de solfejo nas primeiras décadas do século XX, por meio da figura proeminente de João Gomes Júnior, seguida de Carlos Gomes Cardim, Fabiano Lozano, João Batista Julião, Antonio Sá Pereira, em detrimento ao papel principal atribuído nacionalmente a Heitor Villa-Lobos nos anos seguintes, ao menos é importante mencionar que ambas iniciativas [canto coral e solfejo] já se apresentavam nas escolas públicas paulistas antes mesmo do feito aglutinador de Villa-Lobos no país, que imprimiria às rotinas escolares a orientação disciplinadora ${ }^{5}$ dos corpos e mentes (FUKS, 1991, p. 52). Nas palavras de Rosa Fuks, o fato de a metodologia de VillaLobos ter conquistado uma abrangência nacional, enquanto "o trabalho dos paulistas limitou-se ao estado de São Paulo, fez com que a memória brasileira registrasse o canto orfeônico como marco inicial" (1991, p. 102).

Partindo desta memória coletiva, que considera o canto orfeônico a iniciativa mais relevante e sistematizada da educação musical no âmbito da escola brasileira, apresenta-se o registro das ideias de apreciação musical e o repertório presentes em sete manuais didáticos das décadas de 1930 a 1960.

\footnotetext{
${ }^{4}$ Seu primeiro diretor foi Heitor Villa-Lobos, que se tornaria a figura mais reconhecida na implantação da educação musical escolar no país entre os anos de 1930 e 1950, baseado na utilização de métodos de solfejo padronizados e na organização dos orfeões, grandes coros de alunos que interpretavam o repertório prescrito nos manuais e materiais de apoio disponibilizados. Daí a denominação mais comum da proposta: Canto Orfeônico.

${ }^{5}$ Fortemente identificada com o caráter nacionalista do governo ditatorial imposto ao país à época. A discussão sobre a identificação de Villa-Lobos com o regime e o seu grau de envolvimento no aparelho estatal ainda é assunto debatido no âmbito da academia, onde se apresentam entusiastas e detratores de sua proposta.
} 


\section{O canto orfeônico: as ideias e o repertório para a apreciação musical na escola brasileira}

Entre os anos de 1931 e 1961, a educação musical no Brasil esteve essencialmente ligada ao canto orfeônico que, incentivando a predominância dos hinos patrióticos e canções folclóricas, assumia fortemente objetivos de formação cívica e moral (FUKS, 2007). A receita prescrita por Villa-Lobos, de seu canto orfeônico para "educar socialmente as crianças" (VILLA-LOBOS, 1987, p. 13), estava impregnada do civismo e ideias nacionalistas em voga à época. Tratava-se de um projeto inserido em uma "abordagem tradicional do ensino de música [...] baseado em modelos imitativos, direcionados aos objetivos e metas do programa" (HENTSCHKE; OLIVEIRA, 2000, p. 47), que explorava o aspecto funcional da música - dentro do projeto cívico getulista - e encontrou seu declínio a partir da década de 1950, ao final do Estado Novo.

Ao analisar o canto orfeônico, Fucci-Amato (2007) avança na mesma trilha, argumentando que este movimento pode ser entendido, tal como relatado por VillaLobos em suas obras e entrevistas, "na perspectiva do desenvolvimento do cidadão brasileiro, [...] já que a música foi por ele considerada um fato intimamente ligado à coletividade" (FUCCI-AMATO, 2007, p. 81). Especificamente quanto ao repertório para apreciação musical na escola, a autora rememora que o canto coral concebido por Villa-Lobos "também se preocupou com a valorização das raízes culturais do país. O compositor dedicou grande parte de seus guias de Canto Orfeônico a canções tradicionais e folclóricas" (FUCCI-AMATO, 2007, p. 82).

Observo que os métodos empreendidos por compositores-educadores, como nos casos de Béla Bartok [na Hungria] e Villa-Lobos [no Brasil], tinham forte preocupação com o emprego de materiais musicais ligados ao folclore nacional. Entretanto, esta não era demandada por uma necessidade primordial de aprofundar o conhecimento e apreciação dos gêneros musicais cultivados nacionalmente, mas sim, de extrair recursos musicais [melódicos, harmônicos ou simplesmente rítmicos] para gerassem identificação e proximidade com seu público, objetivando o incremento da performance individual ou em grupo. Nesse sentido, suas abordagens pedagógicas, ao pretenderem trazer algo familiar e facilmente identificável pelos alunos, são elogiáveis.

Não obstante sua reconhecível genuflexão ao gênio de Villa-Lobos, Vasco Mariz (2005) reconhece que o músico "nunca foi um professor na expressão da palavra. Ensinou esporadicamente, mas não teve tempo e talvez paciência para ministrar classes com regularidade" (MARIZ, 2005, p. 156), portanto, não surpreende que os ideais 
educacionais e artísticos não predominassem em sua proposta, mas sim, as preocupações disciplinadoras e cívicas.

Se o programa educacional oficial do canto orfeônico sugeria "palestras sobre a música e os músicos no Brasil, audições de discos comentadas e o discernimento dos diferentes gêneros musicais" (VILLA-LOBOS, 1937), os manuais didáticos do período não materializaram estas ideias. A seguir, apresentamos os momentos específicos em que eles abordaram a apreciação musical nas publicações e o repertório [ocasionalmente] sugerido para escuta:

\section{Manual 1 - Canto orfeônico, volumes 1 e 2, de Heitor Villa-Lobos (1937)}

A pedra angular dos manuais didáticos do período, o Canto Orfeônico de Heitor Villa-Lobos, foi publicado em dois volumes, em 1937 e 1951, tendo sido adotado oficialmente nas escolas públicas e nos cursos de formação de professores da SEMA. Estes manuais destinavam-se aos alunos e também aos próprios professores que o programa pretendia formar.

A apreciação musical é tratada especificamente apenas no segundo volume, quando menciona a necessidade de variedade de repertório para a formação do aluno, sem, no entanto, avançar sobre a temática.

\section{Manual 2 - Música para a escola elementar, INEP (1955)}

O livro publicado pelo Instituto Nacional de Estudos Pedagógicos [INEP], reunia a transcrição em partitura de hinos e marchas oficiais, canções de exaltação nacionalista, folclore brasileiro, canções para acompanhar a rotina escolar ou para pontuar datas comemorativas. Não há menção alguma à apreciação musical na escola ou mediada pelo professor, e a preocupação evidente do manual também recaía sobre a performance, pois almejava "auxiliar ao professor primário na parte musical adaptada a esse nível e a ser cantada a uma voz" (INEP, 1955, p. 09).

\section{Manual 3 - Canto orfeônico, de Osmundo Ribeiro (1955)}

Este manual era parte de uma coleção dedicada às séries do curso ginasial. A apreciação musical era citada apenas na transcrição do programa oficial para o canto orfeônico na primeira série ginasial, e nas possibilidades de usar as canções dispostas no 
material, já na vida adulta, para encontrar "nos momentos difíceis da vida, lenitivo para as mágoas, tônico para os nervos, paz para o espírito" (RIBEIRO, 1955, p. 08). Ao final da publicação, o autor relaciona uma série de hinos cívicos, coros e canções folclóricas transcritas em partitura, com a finalidade de subsidiar as performances escolares, sem recomendação mais específica sobre a apreciação destas ou de outras obras.

\section{Manual 4 - Elementos de canto orfeônico, de Yolanda de Quadros Arruda (1945)}

Tratava-se de um guia destinado aos alunos e professores, conforme seu prefácio e recomendações iniciais. A apreciação musical, como parte do programa curricular oficial, recebeu um capítulo específico na publicação de Yolanda de Quadros Arruda, denominado "História e apreciação musical” (ARRUDA, 1945, p. 186-225), com itens diretamente extraídos dos referenciais da época.

Em seus diferentes tópicos, como o que versa sobre a "finalidade do canto orfeônico" (ARRUDA, 1945, p.187), a preocupação com o civismo é precípua. O "conhecimento dos instrumentos de banda e orquestra" (ARRUDA, 1945, p. 218-219) apresenta informações sobre as famílias e tipos de instrumentos em duas páginas, em um exercício meramente descritivo, e sem relacioná-las às possíveis experiências de escuta dos timbres destes instrumentos.

Em “palestras sobre audições e concertos” (ARRUDA, 1945, p. 217), a autora sugere um possível percurso para orientar a apreciação musical, que transcrevo a seguir:

As palestras sobre audições ou concertos, propositadamente preparados para assistência do mestre e alunos, poderão redundar em comentários e críticas construtivas, em que se lance um olhar de conjunto sobre a organização do programa e sua execução, passandose em seguida aos pormenores que maior interesse tenham despertado ou que sejam dignos de menção por algum motivo.

No caso de possibilitar a assistência a algum concerto público, então o professor poderá comentar com os discípulos sobre outros pontos: como decorreu a audição, qual o programa executado, como se portou o solista ou o conjunto, qual a impressão da assistência, qual a opinião dos críticos da imprensa e qual a opinião pessoal do mestre e dos alunos.

Estes pequenos comentários e palestras simples, feitas com frequência, despertarão nos jovens o gosto pelas realizações musicais, contribuindo assim, com eficácia, para sua formação artístico-cultural (ARRUDA, 1945, p. 217). 
Estas diretrizes nos permitem alguns destaques: a) trata-se de um percurso para a formação de plateias para os tradicionais concertos de música de matriz europeia; b) recomenda-se o uso de concertos didáticos para o trabalho da apreciação; c) sugere o uso frequente de discussões e pequenas palestras como recurso didático nas classes; d) há um espaço para abrigar o posicionamento dos alunos sobre o que ouviram, ombreando-o aos críticos da imprensa e ao próprio mestre.

Finalmente, observo que ao trabalhar o item "discernimento das tonalidades maiores e menores" (ARRUDA, 1945, p. 223), a autora sugere que seja trabalhado por meio de ditados pedagógicos adequados, passando ao "auxílio da audição de discos, selecionados para tal fim" (ARRUDA, 1945, p. 223). Indicação idêntica é fornecida em "discernimento dos gêneros musicais" da música de concerto sem, no entanto, acrescentar nenhuma indicação específica ou orientação adicional ao professor.

Manual 5 - O canto orfeônico no curso secundário, de Florêncio de Almeida Lima (1954)

Este manual propunha, em sua introdução, ser uma "nova contribuição ao ensino de canto orfeônico" (LIMA, 1954, sn.) para as séries do curso secundário. No entanto, sua divisão por planos de aulas não contemplava a apreciação como atividade educacional específica, restringindo os conteúdos ao repertório para performance, exercícios de solfejo e informações biográficas e históricas referentes à música de concerto europeia.

Manual 6 - Aulas de canto orfeônico, de Judith Morrison de Almeida (1955)

O livro é dividido em quatro grandes partes, articulando teoria musical, cultura geral [informações históricas da música, instrumentação], biografia e prática [repertório para performance]. No entanto, apesar de afirmar em apenas um parágrafo que o canto orfeônico desenvolveria “o juízo estético musical do aluno, preparando-o para que no futuro possa discernir, na música, o nobre do vulgar, se torne bom ouvinte, crítico sincero, com elevação moral e artística" (ALMEIDA, 1955, p.38), não trata em momento algum das atividades de apreciação possíveis no âmbito escolar.

Manual 7 - Manual de canto orfeônico, de Luís do Rego (1952) 
Destinado ao curso ginasial, o manual apresenta lições de teoria musical, história da música, solfejos, instrumentação, biografia e repertório para o canto orfeônico. Novamente, não há menção às atividades de apreciação sob qualquer aspecto.

Sintetizando as informações presentes nos livros, ficam claras as disposições dos manuais didáticos do período: a apreciação musical, apesar de ser parte do programa educacional oficial para os diferentes níveis de ensino, seria permanentemente negligenciada nos volumes destinados aos alunos e professores, com exceção da publicação de Yolanda Arruda (1945). Seria ela também a única a referenciar o uso de gravações ou discos nos sete manuais.

Alguns questionamentos permanecem para futuras pesquisas: seria uma resistência ao uso das tecnologias na escola por estes autores? Uma preocupação educacional que não teria sido consolidada até aquele momento?

\section{Como ficou a apreciação musical na escola posteriormente?}

Um exemplo de programa escolar de apreciação oficialmente organizado viria posteriormente em Caldeira Filho (1971); ou nas recomendações tardias da Técnica de Educação do Estado da Guanabara, a professora Emília Jannibelli (1971), e poderiam ser disseminados com a ajuda do fonógrafo. Enquanto o primeiro apontava diretrizes para a escuta do repertório variado, o último contava com hinos, marchas escolares, canções folclóricas do Brasil e dos países americanos nas séries iniciais; e obras de 'vultos' como Saint-Saens, Carlos Gomes, Villa-Lobos, Radamés Gnatalli para as séries finais (JANNIBELLI, 1971).

No momento em que o canto orfeônico estava sendo abandonado, o fonógrafo ganharia visibilidade como recurso pedagógico, e acabaria prestigiado nos tomos de Caldeira Filho (1971) e Jannibelli (1971). Não há uma pesquisa sobre o assunto, mas reconhecendo as carências materiais históricas da educação nacional, é bem provável que o fonógrafo ou outros dispositivos não tenham sido disponibilizados à totalidade das escolas públicas brasileiras e em número suficiente. Considere-se que as recomendações de Jannibelli (1971) são tardias, em razão de abordarem um programa educacional datado de 1967, momento em que o canto orfeônico já estava oficialmente em desuso [desde 1961] e a educação musical escolar [com professores formados para o trabalho pedagógico orfeônico] vivia seu crepúsculo, além de, simultaneamente, se tratar de uma época em que os discos de vinil estavam bem mais popularizados no 
Brasil, em relação aos anos de 1930 ou 40. Portanto, fica difícil avaliar a abrangência deste tipo de desenvolvimento curricular em larga escala, como proposto por estes autores.

Posta a saída de cena progressiva do canto orfeônico, a partir dos anos de 1961, as tensões entre a música popular e a música erudita na academia e no interior da escola pública se intensificaram. Ao mencionar uma cadeia de eventos relacionados à chegada de Hans J. Koellreuter ao Brasil, o final do Estado Novo, as alternativas de uso da criatividade na pedagogia [por meio das oficinas de música] e a introdução das diferentes vanguardas composicionais europeias em terras brasileiras, Fuks (1991) identifica muitas das práticas escolares do pós-guerra, sem mencionar especificamente a apreciação musical.

Verifica-se, entretanto, que a introdução de elementos das oficinas de música nas escolas, contemplando um repertório mais amplo, é documentada por meio de alguns depoimentos de expoentes (FUKS, 1991), mas não há clareza de que as práticas de exploração de variados materiais musicais e repertórios tenham sido sistematicamente adotadas nas salas de aula de todo país.

A exceção é quando a autora informa que a maioria das alunas da escola normal no Rio de Janeiro era jovem e dedicava "grande parte do seu tempo de lazer a ouvir o rádio" (FUKS, 1991, p. 137). É o advento da cultura jovem e de suas preferências musicais no Brasil. O rádio se ocupou em tentar fornecer, ao menos em parte, material para esta apreciação musical escolar. Mas as tentativas não foram suficientemente sistematizadas ou registradas sob o enfoque da escola.

Alguns eventos ajudariam a localizar estas transformações na apreciação musical dos indivíduos, não apenas no Brasil, mas especialmente nas sociedades de consumo de corte ocidental. Simon Frith destaca, no trecho traduzido por Michel Herschmann,

[...] que a primeira revolução na indústria da música foi deflagrada pelo emprego da imprensa às partituras. [...] Uma segunda revolução resultou do desenvolvimento das tecnologias de gravação, que permitiram armazenamento em discos e cilindros. A partir daí se passou a ter música em casa, sem necessariamente se dominar o ofício de 'fazer música'. [...] O fonógrafo veio a significar que as atuações musicais públicas podiam agora ser escutadas no âmbito doméstico. $\mathrm{O}$ gramofone portátil e o transmissor de rádio deslocaram a experiência musical até o dormitório. O walkman da Sony possibilitou que cada indivíduo confeccionasse seleções musicais para sua audição pessoal, inclusive nos espaços públicos (2010, p. 114-116). 
A apreciação da música, que sempre teve uma função coletiva ${ }^{6}$, passou a ficar cada vez mais individualizada, apesar da popularização ao acesso. $\mathrm{O}$ ponto de origem do fenômeno costuma acompanhar o advento de uma cultura jovem, posto no fim da Segunda Guerra Mundial (BENNETT, 2000), e que coincide com a disseminação dos aparelhos de reprodução portáteis [inicialmente rádios, gravadores em fita e vitrolas], bem como a fabricação dos instrumentos musicais eletrificados e mais baratos (MORAES; SALIBA, 2010).

Em âmbito distinto, o da academia, a disseminação das ideias de autores como Murray Schafer (1991) e Keith Swanwick $(2003)^{7}$ contribuiu, a partir da década de 1990, para emprestar uma dimensão proeminente às atividades de apreciação musical na escola, repondo-a ao seu lugar de destaque nas atividades pedagógicas.

Lembremos, finalmente, que em paralelo aos Planos Nacional e estaduais de Educação de 2014, a nova Base Nacional Comum Curricular [BNCC] foi posta à mesa para debates, o que incluiu uma ampla consulta pública entre setembro de 2015 e março de 2016. A versão preliminar número 2 deste documento elencava as principais competências musicais a serem abordadas no currículo formal de todo o ciclo básico, e incluía o reconhecimento ao patrimônio musical de culturas diversas; a compreensão dos usos e funções da música em seus contextos de produção e circulação; a apropriação das tecnologias para apreciação e produção musical; e o compartilhamento das aprendizagens musicais com a comunidade escolar e a sociedade (MEC, 2016), todas estas competências diretamente ligadas às atividades de apreciação.

Por se tratar de matéria controversa, e que ficou pendente entre as sucessivas mudanças no Ministério da Educação durante o período político conturbado vivido pelo país, a BNCC ainda teria uma terceira versão do seu texto apresentada no dia 26 de janeiro de 2017, e provavelmente não definitiva (MEC, 2017). Alerto, portanto, que estas considerações feitas sobre a BNCC são provisórias, mas contribuem para situar a discussão sobre o momento atual.

6 “A música sempre teve uma função coletiva, e mesmo quando compramos discos e revistas ou escutamos rádio, fazemos isso com o objetivo de nos sentir parte de uma determinada coletividade que compartilha gostos e códigos sociais" (HERSCHMANN, 2010, p.116). Isso também valeria para as idas aos concertos ou igrejas.

${ }^{7}$ Dois autores que tiveram forte inserção na academia e nos documentos oficiais relacionados à presença da música na educação básica no referido período. 


\section{Considerações finais}

Ao final deste breve resgate, é importante ressaltar que os elementos para compor uma história da apreciação musical na educação escolar brasileira são mínimos e fragmentados. Marisa Fonterrada (2008), em obra fundamental da educação musical brasileira, reconhecia que até o final do período imperial, quase não havia "referências à maneira pela qual o ensino da música se dava, a não ser quanto ao repertório, predominantemente europeu" (FONTERRADA, 2008, p. 209-210). Nas décadas seguintes à Proclamação da República, quando ocorreu a implantação do canto orfeônico na década de 1930, o repertório escolar foi fortemente baseado nas tradições folclóricas coletadas e transcritas nos manuais pedagógicos, bem como nos hinos e cânticos cívicos.

Foi necessário deter-se na perspectiva do canto orfeônico, por se tratar do programa educacional mais importante em âmbito nacional até a atualidade, não apenas na abrangência do número e localidade das escolas, mas na vultuosidade, investimentos e ambições da proposta, que pretendia uniformizar as práticas educacionais no país.

No entanto, como verificou-se no estudo dos manuais didáticos ligados à proposta, a preocupação com a apreciação era incipiente e francamente desprestigiada nas atividades escolares. Observo que ela não seria possível como atividade escolar largamente sistematizada no Brasil, ao menos até a segunda metade do século $\mathrm{XX}^{8}$, primeiramente por uma razão tecnológica: as gravações ou registros fonográficos ainda não estavam disponíveis ao público mais amplo no país e muito menos às escolas nos primeiros momentos. Em segundo, porque durante o período áureo do canto orfeônico, a ênfase nas atividades de execução musical e performance coletiva relegou à apreciação musical uma função secundária, desenvolvida na medida em que se tornava necessário dominar o repertório de canções folclóricas ou daquelas elaboradas com fins pedagógicos para as apresentações, atos cívicos ou demarcadoras dos tempos e demais atividades escolares.

${ }^{8}$ George Snyders vislumbrou, no contexto do ensino francês da segunda metade do século XX, esta idêntica "mutação histórica, advinda das novas possibilidades técnicas de reprodução em alta-fidelidade. [...] Tornou-se tecnicamente possível os alunos escutarem, na sala de música ou mesmo numa sala de aula comum, obras musicais, obras-primas, em condição de quase perfeição. Não há mais nenhuma dificuldade para isolar ou repetir uma determinada passagem da obra, para seguir um tema em suas modificações; o professor pode, sem problemas, pedir aos alunos para ouvirem de novo, em suas casas, uma obra estudada em classe. É isto que pode e deve transformar o ensino da música em seu conjunto (SNYDERS, 2008, p.27). 
Nesta perspectiva, entendo que o advento e popularização das gravações é o que nos permitirá tratar a apreciação musical no Brasil como uma atividade possível de ser isolada para fins educacionais, associados à difusão de um tipo de literatura educacional no país que posicionava a escuta no centro de suas abordagens pedagógicas, como a produzida por Murray Schafer (1991, 2009) ou Keith Swanwick (2003, 2014).

Em um contexto atual, além de reconhecermos a centralidade da apreciação musical para o desenvolvimento das atividades de composição ou execução, trata-se também de situá-la como uma atividade escolarizada que diminuiria as desigualdades verificadas entre os alunos da educação básica, sob o aspecto de seu capital cultural. Afinal, sua capacidade de transitar com desenvoltura entre diferentes gêneros e estilos musicais dependeria diretamente, como notaram Pierre Bourdieu e Jean-Claude Passeron $(2015)^{9}$, das condições socioeconômicas e de um entorno familiar que lhes permita o acesso aos concertos e gravações variadas, enquanto os alunos oriundos de famílias menos favorecidas percorreriam um processo de aculturação e aprendizagem mais árduo e extenso, uma vez que comumente não se situam próximos destas manifestações concretas da Arte desde a infância. Se a escola contribuir para a redução destas desigualdades por meio de atividades de apreciação estruturadas em sala de aula e nos espaços ou aparelhos culturais disponíveis, por certo cumprirá o papel designado por Bourdieu e Passeron (2015), de uma finalidade democratizadora das aprendizagens.

\section{REFERÊNCIAS}

ALMEIDA, J. M. Aulas de canto orfeônico. São Paulo: Companhia Editora Nacional, 1955.

ARRUDA, Y. Q. Elementos de canto orfeônico. São Paulo: Companhia Editora Nacional, 1945.

BASTIÃO, Z. A. Apreciação musical expressiva: uma abordagem para a formação de professores de música da educação básica. Salvador: EDUFBA, 2014.

\footnotetext{
${ }^{9}$ Nas palavras dos autores, tomando o caso do ensino superior francês, os "estudantes mais favorecidos não devem somente ao seu meio de origem hábitos, treinamentos e atitudes aplicáveis diretamente às suas tarefas escolares; eles também herdam saberes e um saber-fazer, gostos e um "bom gosto" cuja rentabilidade escolar, por ser indireta, é ainda mais certa. [...] O privilégio cultural é evidente quando se trata da familiaridade com as obras que somente a frequentação regular do teatro, do museu ou do concerto [frequentação que não é organizada pela escola, ou somente de maneira esporádica] pode oferecer". (BOURDIEU; PASSERON, 2015, p.34).
} 
BENNETT, A. Popular music and youth culture: music, identity and place. London: Palgrave, 2000.

BRASIL. MEC. Base Nacional Comum Curricular. Proposta preliminar, $2^{\mathrm{a}}$ versão revista. MEC: Brasília, 2016. Disponível em:

$<$ http://basenacionalcomum.mec.gov.br/documentos/bncc-2versao.revista.pdf $>$. Acesso em 02 fev. 2017.

BRASIL. MEC. Ministério da Educação apresenta avanços da terceira versão da Base Comum Curricular. Disponível em:

$<$ http://portal.mec.gov.br/component/content/index.php?option=com_content\&view=art icle \&id=44481:ministerio-da-educacao-apresenta-avancos-da-terceira-versao-da-basecomum-curricular\&catid=211\&Itemid=86> . Acesso em: 02 fev. 2017.

BOURDIEU, P.; PASSERON, J-C. Os herdeiros: os estudantes e a cultura. Florianópolis: Editora UFSC, 2015.

CASTAGNA, P. Música na América portuguesa. In: MORAES, J. G. V; SALIBA, E. T. (Org). História e música no Brasil. São Paulo: Alameda, 2010. p. 35-78.

COPLAND, A. Como ouvir e entender música. Rio de Janeiro: Artenova, 1974.

FILHO, C. Apreciação musical: subsídios técnico-estéticos. São Paulo: Fermata do Brasil, 1971.

FONTERRADA, M. T. O. De tramas e fios: um ensaio sobre música e educação. 2 ed. São Paulo: UNESP / FUNARTE, 2008.

FUCCI-AMATO, R. Escola e educação musical: (des) caminhos históricos e horizontes. Campinas: Papirus, 2012.

FUCCI-AMATO, R. Breve retrospectiva histórica e desafios do ensino de música na educação básica brasileira. Revista Opus, v. 12, p. 144-166, 2006.

FUCCI-AMATO, R. O canto coral como prática sócio-cultural e educativo-musical. Revista Opus, v. 13, n. 1, p. 75-96, jun., 2007.

FUKS, R. O discurso do silêncio. Rio de Janeiro: Enelivros, 1991.

FUKS, R. A educação musical da Era Vargas: seus precursores. In: OLIVEIRA, A.; CAJAZEIRA, R. (Org.). Educação Musical no Brasil. Salvador: P\&A, 2007. p. 18-23.

HARGREAVES, D. J; HARGREAVES, J. J.; NORTH, A. C. Imagination and creativity in music listening. In: HARGREAVES, D.; MIELL, D.; MACDONALD, R. Musical imaginations: multidisciplinary perspectives in creativity, performance and perception. London, New York: Oxford University Press, 2012. p. 156-172.

HENTSCHKE, L.; OLIVEIRA, A. Educação musical no Brasil. In: HENTSCHKE, L. (Org.). Educação musical em países de línguas neolatinas. Porto Alegre: Editora Universidade/UFRGS, 2000. p. 47-64. 
HERSCHMANN, M. Indústria da música em transição. São Paulo: Estação das Letras e Cores, 2010.

INEP. Música para a escola elementar. Rio de Janeiro: Instituto Nacional de Estudos Pedagógicos, 1955.

JANNIBELLI, E. D. A musicalização na escola. Rio de Janeiro: Lidador, 1971.

JULIA, D. A cultura escolar como objeto histórico. Revista Brasileira de História da Educação, n. 1, p. 09-43, jan./jun., 2001.

LAZZARIN, L. F. Ouvir música com significado: um desafio possível. In: BEYER, E. (Org). Ideias em educação musical. Porto Alegre: Editora Mediação 1999. p. 74-87.

LIMA, F. A. O canto orfeônico no curso secundário. São Paulo: Editora Paulo de Azevedo, 1954.

MARIZ, V. História da música no Brasil. Rio de Janeiro: Nova Fronteira, 2005.

MORAES, J. G. V.; SALIBA, E. T. (Org). História e música no Brasil. São Paulo: Alameda, 2010.

NOGUEIRA, L. W. M. Música em Campinas nos últimos anos do Império. Campinas: Editora da Unicamp, CMU, 2001.

OLIVEIRA, A.; CAJAZEIRA, R. (Org.) Educação musical no Brasil. Salvador: P \& A, 2007.

REGO, L. Manual de canto orfeônico. Porto Alegre: Editora Globo, 1952.

REIMER, B. A philosophy of music education. New Jersey: Prentice Hall, 1989.

RIBEIRO, O. Canto orfêonico - primeira série. São Paulo: Editora Paulo de Azevedo, 1955.

SCHAFER, M. O ouvido pensante. São Paulo: UNESP, 1991.

SCHAFER, M. Educação sonora. São Paulo: Editora Melhoramentos, 2009.

SNYDERS, G. A escola pode ensinar as alegrias da música? São Paulo: Cortez, 2008.

SOUZA, J. A educação musical no Brasil dos anos 1930-1945. In: OLIVEIRA, A;

CAJAZEIRA, R. (Org.) Educação musical no Brasil. Salvador: P \& A, 2007. p. 13-17.

SOUZA, J. Sobre as várias histórias da educação musical no Brasil. Revista da ABEM, Londrina, v. 22, n. 33, p. 109-120, jul./dez. 2014.

SWANWICK, K. Ensinando música musicalmente. São Paulo: Moderna, 2003. 
SWANWICK, K. Música, mente e educação. Belo Horizonte: Autêntica, 2014.

VIDAL, D. G.; FILHO, L. M. As lentes da história: estudos de história e historiografia no Brasil. Campinas: Autores Associados, 2005.

VILLA-LOBOS, H. Canto orfeônico - $1^{\circ}$ volume. Rio de Janeiro; São Paulo: Irmãos Vitale, 1937.

VILLA-LOBOS, H. Canto orfeônico - $2^{\circ}$ volume. Rio de Janeiro; São Paulo: Irmãos Vitale, 1951.

VILLA-LOBOS, H. Villa-Lobos por ele mesmo - pensamentos. In: RIBEIRO, J. C. (Org.). O pensamento vivo de Villa-Lobos. São Paulo: Martin Claret, 1987.

WUYTACK, J.; PALHEIROS, G. B. Audição musical activa. Porto: Associação Wuytack de Pedagogia Musical, 1995.

\section{Como referenciar este artigo}

CONSTANTINO, Paulo. Por uma história da apreciação musical na escola brasileira: as ideias dispostas nos manuais didáticos do canto orfeônico. Revista Ibero-Americana de Estudos em Educação, Araraquara, v. 13, n. 4, p. 1814-1831, out./dez., 2018. EISSN: 1982-5587. DOI: 10.21723/riaee.unesp.v13.n4.out/dez.2018.10087

Submetido em: 09/07/2017

Revisões requeridas: 10/11/2017

Aprovado em: 10/05/2018 